\title{
Change in body composition assessed by computed tomography in long-term survivors after esophageal cancer
} surgery

\author{
Yutaka Nakaya*, Masao Yuasa, Kana Atsumi, Yoshihito Furukita, Akira Tangoku, Rie Tsutsumi, Nagakatsu Harada and Hiroshi Sakaue \\ Department of Nutrition and Metabolism, Division of Clinical Technology, and Department of Thoracic, Endocrine Surgery and Oncology, Institute of Biomedi-
} cal sciences, the University of Tokushima Graduate School, Japan

\begin{abstract}
Weight loss especially muscle wasting is of critical importance to cancer patients because of their negative effects on survival, functional status, and tolerability of chemotherapy. This study aimed to clarify changes in body composition in long-tern survivors after esophageal cancer surgery. Twenty-four patients were assessed for serial weight and body composition, at baseline and again until 3 years after surgery. Computed tomography scan was used to assess body composition. These patients manifested a decline in mean body weight from $59.3 \pm 7.5 \mathrm{~kg}$ to $47.5 \pm 8.5 \mathrm{~kg}$ after 24 months $(\mathrm{p}<0.01)$. Then they started to recover their body weight. Abdominal fat mass in men and subcutaneous fat mass in women $(\mathrm{p}<0.05)$ increased significantly, but skeletal muscle area at the L3 vertebral level dropped continuously $(\mathrm{p}<0.05$ in men) even after 2 years.

The patients after surgery for esophageal cancer initially lost their body weight but they regained their body weight after 2 years. However, the increase in body weight was the result of the increase in fat mass, but not of the increase in muscle mass. Special nutrition support and exercise training will be needed to improve their nutritional status.
\end{abstract}

\section{Introduction}

In 2014 global cancer statistics, esophageal cancer was the $7^{\text {th }}$ among the cancer types for estimated deaths [1,2]. Although there have been great improvements in survival over the past 35 years, overall 5 -year survival rates still $\sim 20 \%$ for esophageal cancer $[1,3]$. Weight loss is one of the most pronounced side effects after surgery for esophageal cancer even in long-term disease-free survivors [4,5]. During surgery, part of the lesser curvature of the stomach is removed for reconstruction of gastric tubulization, and they may no longer be able to eat large amount of meals. Treatment side effects like loss of appetite, reflux and stricture and dumping syndrome also make it difficult for patients to maintain weight after surgery. Some of the patients, however, may start to regain their body weight several years after surgery. However, the change in body weight and the body mass index lack accuracy to detect fat free mass (FFM) [6,7]. Among several component of FFM, loss of muscle mass is related to increasing mortality, worse clinical outcomes, and impaired quality of life $[8,9]$. There have been many studies in change in body weight after surgery but no studies evaluated the serial changes in body composition in these patients. In the present study, changes in body composition were studied by computed tomography (CT) among 3 -year survivors after surgery for esophageal cancer. Muscle loss is generally held to be a more serious concern in terms of malnutrition. $\mathrm{CT}$ or magnetic resonance imaging can differentiate muscle from other soft lean tissues although bioelectric impedance or whole-body $\mathrm{K}$ assessments do not distinguish them. Quantification of the loss of muscle mass allows early screening of malnutrition and helps to carry out optimal nutritional support.

\section{Methods}

\section{Studied patients}

From a medical database of Tokushima University Hospital, Tokushima, Japan, 3-year disease-free survivors having undergone a transthoracic esophagectomy with gastric tube reconstruction between 2005 and 2012 were selected retrospectively. Among these patients, we chose 24 patients ( 20 men and 4 women; mean age $67.8 \pm 10.1$ years old) in whom records of body weight and CT were available at least 3 points for 3 years, i.e., (1) 3-6 months, (2)10-24 months, (3) 36 months after surgery). We excluded those who received adjuvant chemotherapy after surgery to exclude the effect of chemotherapy [13]. Laboratory data and CT scan were retrospectively collected from medical records. The Ethics Committee at Tokushima University Hospital approved the study.

\section{Data analysis}

Body weight of the patients was recorded at each visit to outpatient department of the hospital. Body weight was measured at each visit. CT was recorded at random by each doctor according to clinical needs. In order to study the change in body composition, we only chose

Correspondence to: Yutaka Nakaya, Department of Nutrition, Institute of Biomedical sciences, the University of Tokushima Graduate School, Japan, E-mail: nakaya.y@tokushima-u.ac.jp

Keywords: computed tomography, body composition, esophageal cancer, weight loss, sarcopenia

Received: May 26, 2016; Accepted: June 20, 2016; Published: June 23, 2016 
those in whom CT was recorded at least following three time points: (1) 3-6 months, (2)10-24 months, (3) 36 months after surgery. We chose these points from the change in body weight, i.e., in early phase body weight decreased rapidly, then body weight was stable for a while, and then after 36 month body weight started to gain. In some of the patients, data were also available after 4 years. CT at third vertebra (L3) was selected, which section contains visceral and subcutaneous adipose tissue and many muscles (the psoas, paraspinal muscles, transversus abdominus, external and internal oblique abdominals, and rectus abdominus). In this section, skeletal muscle and adipose tissue areas correspond to whole-body tissue quantities for patients with cancer [6]. CT Hounsfield unit ranges used for specific tissues included - 29 to 150 for skeletal muscle, 2190 to 230 for subcutaneous and intermuscular adipose tissue, and -150 to 250 for visceral adipose tissue. Boundaries were corrected manually as necessary. Biochemical evaluation included hemoglobin, CRP, BUN, creatinine and albumin.

Data are expressed as means and standard deviations. The comparison of means was carried out using the paired and unpaired Student $t$ test of. $P$ values $<0.05$ were considered to be significant.

\section{Results}

\section{Change in body weight and BMI}

Table 1 shows baseline characteristics of the studied patients and changes in body weight. Figure 1 shows the change in BMI after surgery. Body weight as well as BMI decreased rapidly initially until 6 months $(\mathrm{p}<0.01)$. The maximum loss of body weight and BMI was $10.1 \pm 3.5$ $\mathrm{kg}$ and $3.96 \pm 1.11 \mathrm{~kg} / \mathrm{m}^{2}$, respectively $(\mathrm{p}<0.01)$. Their body weight was relatively stable between 6 and 24 months, and after then the patients started to regain their body weight and $\mathrm{BMI}$ ( $\mathrm{p}<0.05 ; 24$ vs. 48 month).

Table 1. Baseline characteristics of the studied patients and changes in body weight $(\mathrm{n}=24)$.

\begin{tabular}{|l|c|}
\hline Age $($ year $)$ & $67.8 \pm 10.1$ \\
\hline Height $(\mathrm{m})$ & $1.62 \pm 0.06$ \\
\hline Body weight $(\mathrm{kg})$ & \\
\hline Before operation & $59.3 \pm 7.5$ \\
\hline After operation & $57.1 \pm 6.8$ \\
\hline 6 month & $48.5 \pm 7.8$ \\
\hline 12 month & $50.9 \pm 6.2$ \\
\hline 24 month & $47.5 \pm 8.5$ \\
\hline 36 month & $49.5 \pm 7.9$ \\
\hline 48 month & $49.7 \pm 8.2$ \\
\hline
\end{tabular}

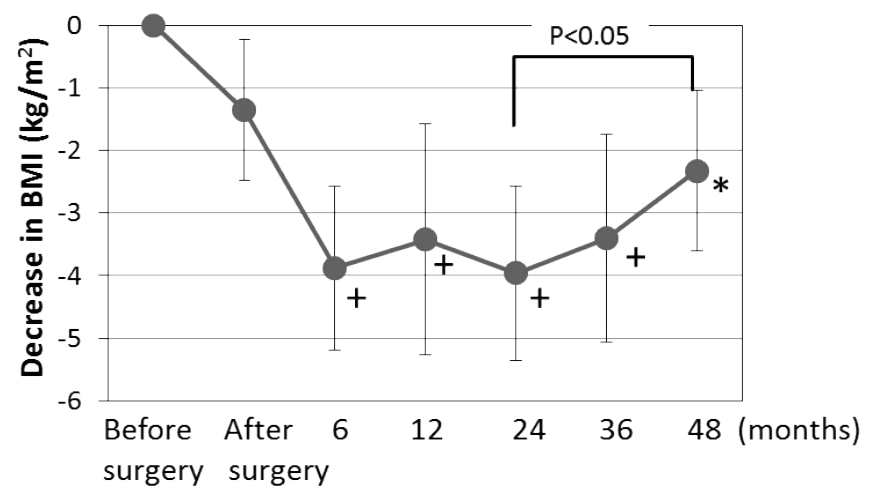

Figure 1. Change in body mass index (BMI) after surgery for esophagus cancer. BMI dropped rapidly early after surgery and is stable between 6 and 24 months. Then, BMI starts to increase after 24 months. + and $*$ are $\mathrm{p}<0.01$ and $\mathrm{p}<0.05 v s$. after surgery.

\section{Changes in body composition}

Figure 2 shows the changes in body composition in total patients. Decreased subcutaneous and visceral fat mass was observed 12 24 months after surgery $(\mathrm{p}<0.05)$, but then these values started to increase similarly with changes in BMI. Muscle mass still continued to decrease after 2 years $(\mathrm{p}<0.05$ in men), suggesting that the recovery of body weight is mostly from fat tissues and not from muscle. Table 2 shows the changes in body composition in men and women. Muscle mass and both visceral and subcutaneous fat masses were decreased at 1-2 years after surgery in both men and women (both $\mathrm{p}<0.01$ ). In men muscle mass was still decreasing $(\mathrm{p}<0.05)$ but not in women after 3 years. Interestingly, after 3 years visceral fat was increased in men $(\mathrm{p}<0.05)$ and subcutaneous fat was increased in women $(\mathrm{p}<0.05)$. Figure 2 also shows change in the serum albumin levels. Serum albumin also recovered at 3 years after surgery $(\mathrm{p}<0.01)$.

We divided these patients into two groups according to the degrees of loss of muscle and compared the incidences of complications (ileus and dehiscence) between those greater and smaller muscle mass before operation. We could not find any significant differences in these complications between two groups, i.e., ileus 2 patients each, and
A. Subcutaneous fat

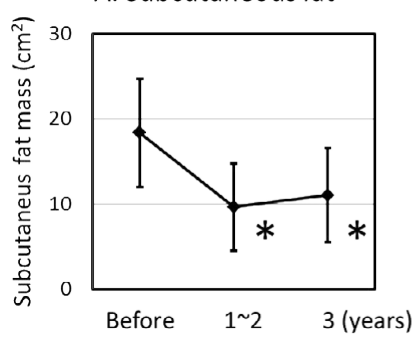

C. Muscle

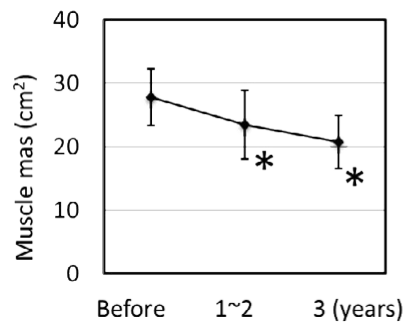

B. Visceral fat

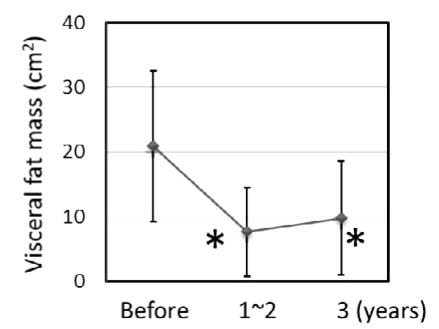

D. Serum albumin

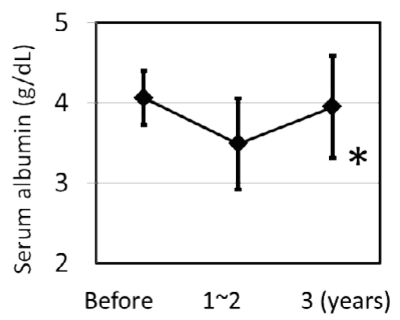

Figure 2. Change in body composition and serum albumin levels after esophagotomy $* \mathrm{p}<0.01$ vs. baseline.

Table 2. Change in body composition after surgery.

\begin{tabular}{|c|c|c|}
\hline & Men $(n=20)$ & Women $(n=4)$ \\
\hline \multicolumn{3}{|c|}{ Muscle mass $\left(\mathrm{cm}^{2}\right)$} \\
\hline Baseline & $28.57 \pm 4.19$ & $23.75 \pm 3.84$ \\
\hline 1-2 years & $24.68 \pm 5.07 * 7+$ & $17.41 \pm 2.74^{*}$ \\
\hline 3 years & $21.57 \pm 4.15^{*}$ & $17.93 \pm 3.92 *$ \\
\hline \multicolumn{3}{|c|}{ Subcutaneous fat $\left(\mathrm{cm}^{2}\right)$} \\
\hline Baseline & $17.85 \pm 5.16$ & $20.93 \pm 11.4$ \\
\hline $1-2$ years & $10.13 \pm 5.15^{*}$ & $7.05 \pm 5.15^{*}$ \\
\hline 3 years & $11.27 \pm 6.34 *$ & $10.25 \pm 1.07 *]$ \\
\hline \multicolumn{3}{|c|}{ Visceral fat $\left(\mathrm{cm}^{2}\right)$} \\
\hline Baseline & $23.22 \pm 11.13$ & $9.26 \pm 6.7$ \\
\hline $1-2$ years & $8.61 \pm 6.95 * 7+$ & $2.77 \pm 3.49^{*}$ \\
\hline 3 years & $11.86 \pm 8.91 *$ & $2.49 \pm 2.09^{*}$ \\
\hline
\end{tabular}

$* \mathrm{p}<0.01 v$ s. baseline, + and $++\mathrm{p}<0.05$ and $\mathrm{p}<0.10$, respectively between indicated groups. 
dehiscence 1 patient in greater muscle mass group and 2 patients in smaller muscle mass group. As they were the survivors, we could not compare survival rate.

\section{Discussion}

Body composition evaluation is a valuable technique to assess nutritional status. In the present study, we measured the change in body composition in patients after surgery for esophageal cancer using computed tomography. The patients lost their body weight early stage after surgery, but most of the survivors started to increase their body weight after 24 months. Both fat and muscle tissue significantly decreased in early stages after surgery. After 2 years, fat tissue increased, i.e., visceral fat in men and subcutaneous fat in women, respectively (both $\mathrm{p}<0.05$ ), but muscle mass did not increase.

Loss of muscle mass is related to mortality in patients with chronic diseases [14], cancer, and elderly patients in long-stay facilities [15]. As the sensitivity of BMI for detecting loss of muscle mass is reduced, increased body weight did not reflect muscle mass in survivors with esophageal cancer surgery. In agreement with our study, after hematopoietic stem cell transplantation, the increase in BMI is the result of the increase in fat mass, but not of the increase in FFM [16]. Also, during recovery after an acute illness, weight gain 6 months after ICU discharge could be mostly related to an increase in fat mass $(+7 \mathrm{~kg})$ while fat free mass only increased by $2 \mathrm{~kg}$. By identifying the patients gaining weight but reporting no or insufficient FFM, body composition evaluation could contribute to influencing the nutritional support that would have been stopped in the absence of body composition evaluation.

The detection of malnutrition is usually based on measurements of weight and height, calculations of BMI, and the percentage of weight loss. Evaluation of body composition is valuable to assess nutritional status. In 441 patients with non-small cell lung cancer, FFM loss determined by computerized tomography (CT) was observed in each BMI category [17], and in young adults with all types of cancer, an increase in FM together with a decrease in FFM were reported.

FFM loss is correlated with survival in different clinical settings [17-19]. Thus, administering the same doses of chemotherapy drugs to a patient with a low FFM compared to a patient with a normal FFM would increase the risk of chemotherapy toxicity [19]. These data suggest that FFM loss could have a direct impact on the clinical outcome of cancer patients.

Recently, CT was used to evaluate the disease prognosis in relation to muscle wasting. In cancer patients, sarcopenia as assessed by CT measurement of the total skeletal muscle cross-sectional area is an independent predictor of the survival of patients with hematopoietic [17], bronchopulmonary [18], gastrointestinal [19], and pancreatic cancers [20]. These data suggest that FFM loss could have a direct impact on the clinical outcome of cancer patients. As muscle is biggest protein storage in the body and it gives an evaluation of nutritional status. Muscle mass also allows evaluation of the disease prognosis and outcome [18-20].

In the present study, body weight was checked frequently, but we could not obtain CT data at the same timing, as this study was not prospective. Therefore, this study did not reveal the features of all patients after esophageal surgery. All studied patients we chose, showed relatively better clinical course after surgery than those who were ill or died. Thus we could not compare the effect of body muscle mass on prognosis or adverse effects. However, the results of our study showed muscle mass wasting still continued long after surgery even in these patients.

\section{Conclusion}

Diagnostic computer tomography can be used to assess body composition and may be useful for nutritional assessment in patients after esophageal cancer surgery. These patients initially lost both fat and muscle after surgery, but they regained their body weight after 2 years. However, the increase in body weight was the result of the increase in fat mass, but not of muscle mass, suggesting that nutritional compromise persists in long-term survivors of esophageal cancer operation. This study only showed the change in body composition, and we do not know how to prevent muscle wasting in these patients. The complexity of treating esophageal and gastric cancer necessitates the need for a multimodality approach [21,22]. Special nutrition support including exercise training should be tested in the future to improve their nutritional status.

\section{References}

1. Siegel R, Ma J, Zou Z, Jemal A (2014) Cancer statistics, 2014. CA Cancer J Clin 64 9-29. [Crossref]

2. Eser S, Mathers C, Rebelo M, Parkin DM, Forman D, et al. (2015) Cancer incidence and mortality worldwide: sources, methods and major patterns in GLOBOCAN 2012. Int $J$ Cancer 136: E359-E386.

3. NIH [webpage on the Internet]. SEER Cancer Statistics Review, 1975-2012. 2014 Available from: http://seer.cancer.gov/csr/1975_2012/.

4. Martin L, Lagergren P (2009) Long-term weight change after oesophageal cancer surgery. Br J Surg 96: 1308-1314.

5. Ouattara M, D'Journo XB, Loundou A, Trousse D, Dahan L, et al. (2012) Body mass index kinetics and risk factors of malnutrition one year after radical oesophagectomy for cancer. Eur J Cardiothorac Surg 41: 1088-1093. [Crossref]

6. Hamaguchi Y, Kaido T, Okumura S, Kobayashi A, Hammad A, et al. (2016) Proposa for new diagnostic criteria for low skeletal muscle mass based on computed tomography imaging in Asian adults. Nutrition.

7. Kyle UG, Morabia A, Slosman DO, Mensi N, Unger P, et al. (2001) Contribution of body composition to nutritional assessment at hospital admission in 995 patients: a controlled population study. Br J Nutr 86: 725-731.

8. Fearon K, Strasser F, Anker SD, Bosaeus I, Bruera E, et al. (2011) Definition and classification of cancer cachexia: an international consensus. Lancet Oncol. 12: 489495 .

9. Muscaritoli M, Molfino A, Gioia G, Laviano A, Rossi Fanelli F (2011) The "paralle pathway": a novel nutritional and metabolic approach to cancer patients. Intern Emerg Med 6: 105-12.

10. Heneghan HM, Zaborowski A, Fanning M, McHugh A, Doyle S, et al. (2015) Prospective Study of Malabsorption and Malnutrition After Esophageal and Gastric Cancer Surgery. Ann Surg 262: 803-807. [Crossref]

11. Cheng Y, Wang N, Wang K, Wang J, Tan B, et al. (2013) Prognostic value of body mass index for patients undergoing esophagectomy for esophageal squamous cell carcinoma. Jpn J Clin Oncol. 43: 146-53.

12. Ligthart-Melis GC, Weijs PJ, te Boveldt ND, Buskermolen S, Earthman CP, et al (2013) Dietician-delivered intensive nutritional support is associated with a decrease in severe postoperative complications after surgery in patients with esophageal cancer. Dis Esophagus. 26: 587-93.

13. Moorcraft SY, Smyth EC, Cunningham D (2015) Adjuvant or neoadjuvant therapy for operable esophagogastric cancer? Gastric Cancer 18: 1-10. [Crossref]

14. Futter JE, Cleland JG, Clark AL (2011) Body mass indices and outcome in patients with chronic heart failure. Eur J Heart Fail 13: 207-213. [Crossref]

15. Landi F, Liperoti R, Fusco D, Mastropaolo S, Quattrociocchi D, et al. (2012) Prevalence and risk factors of sarcopenia among nursing home older residents. J Gerontol A Biol Sci Med Sci 67: 48-55. [Crossref]

16. Mourtzakis M, Prado CMM, Lieffers JR, Reiman T, McCargar LJ, et al. (2008) A practical and precise approach to quantification of body composition in cancer patients 
using computed tomography images acquired during routine care. Appl Physiol Nutr Metab 33: 997-1006.

17. Kyle UG, Chalandon Y, Miralbell R, Karsegard VL, Hans D, et al. (2005) Longitudinal follow-up of body composition in hematopoietic stem cell transplant patients. Bone Marrow Transplant 35: 1171-1177. [Crossref]

18. Baracos VE, Reiman T, Mourtzakis M, Gioulbasanis I, Antoun S (2010) Body composition in patients with non-small cell lung cancer: a contemporary view of cancer cachexia with the use of computed tomography image analysis. Am J Clin Nutr 91: 1133S-1137S. [Crossref]

19. Prado CM, Lieffers JR, McCargar LJ, Reiman T, Sawyer MB, et al. (2008) Prevalence and clinical implications of sarcopenic obesity in patients with solid tumours of the respiratory and gastrointestinal tracts: a population-based study. Lancet Oncol 9 : 629-35.

20. Tan BH, Birdsell LA, Martin L, Baracos VE, Fearon KC (2009) Sarcopenia in an overweight or obese patient is an adverse prognostic factor in pancreatic cancer. Clin Cancer Res 15: 6973-6979. [Crossref]

21. Boniface MM, Wani SB, Schefter TE, Koo PJ, Meguid C1, et al. (2016) Multidisciplinary management for esophageal and gastric cancer. Cancer Manag Res 8: 39-44. [Crossref]

22. van Hagen P, Spaander MC, van der Gaast A, van Rij CM, Tilanus HW, et al. (2013) Impact of a multidisciplinary tumour board meeting for upper-GI malignancies on clinical decision making: a prospective cohort study. Int J Clin Oncol 18: 214-219.

Copyright: ( 2016 Nakaya Y. This is an open-access article distributed under the terms of the Creative Commons Attribution License, which permits unrestricted use, distribution, and reproduction in any medium, provided the original author and source are credited. 